\title{
AJK2015-33501
}

\section{NUMERICAL STUDY OF PUMP-TURBINE INSTABILITIES UNDER PUMPING MODE OFF-DESIGN CONDITIONS}

\author{
Uroš Ješe \\ Univ. Grenoble Alpes, LEGI, \\ Grenoble, France
}

\author{
Regiane Fortes-Patella ${ }^{1}$ \\ Univ. Grenoble Alpes, LEGI, \\ Grenoble, France
}

\author{
Matevž Dular \\ University of Ljubljana, LVTS \\ Ljubljana, Slovenia
}

\begin{abstract}
Pumped storage power plants, using reversible pumpturbines, are a great solution to maintain the stability of an electrical network. The continuous operating area of reversible pump-turbines machines is usually delimited by cavitation or a hydraulic instability called hump phenomena at part load. If the machine operates under these off-design conditions, it might be exposed to vibrations and performance losses.

The paper focuses on the numerical analysis of the pumping mode regime and pays special attention to the prediction of the hump shaped characteristic curve and associated rotating stall. The investigations were made on a high head pump-turbine design (nq=27) at model scale for four different guide vane opening angles and a wide range of flow rates. Numerical simulations were performed and analyzed in LEGI and were compared to the global experimental data, provided by Alstom Hydro.
\end{abstract}

\section{INTRODUCTION}

The main energy systems challenges are storing and recovering of a large amount of energy in a short time. One of the most effective available solutions is the Pumped Storage Power Plant (PSP), using reversible pump-turbine. The electrical grids nowadays are not very flexible and cannot accept significant variation between the supply and demand. In order to maintain the stability of the electrical grid, the reversible pump-turbines are subject to switching between the pumping and the generating mode several times per day (even up to 10 and more). Moreover, the continuous operating area of the reversible pump-turbine machines should be free of hydraulic instabilities. However, for generating as well as for pumping operation, some of the hydraulic instabilities can limit the continuous operating range.

${ }^{1}$ Researcher expert of the storage program at the Supergrid institute
At part-load, in pumping mode, the two main sources of instabilities are the presence of the cavitation and the hump zone. Both phenomena can lead to unsteadiness and even to a shift of the operating point with a significant modification of discharge and a drop of efficiency. With no specific investigation of these phenomena and design optimization, the machine may face vibrations, loss of performance and possibly erosion in a case of long time operation.

\section{PUMPING MODE INSTABILITIES}

The rotating stall phenomena have been initially investigated for axial and centrifugal compressors [1-3]. First detailed explanations were given by [4] in 1959, but the rotating stall investigations on the centrifugal geometry were performed much later. During the investigation of the rotor-stator interactions, Arndt [5, 6] showed that the pressure fluctuations are higher on the suction side of the diffuser vanes and are strongly influenced by the radial gap between the trailing edge of the impeller and the leading edge of the diffuser. Moreover, Sano $[7,8]$ stated that wider radial clearance between the impeller and the diffuser causes easier occurrence of the diffuser rotating stall due to decoupling of the impeller/diffuser flow.

In case of the pump-turbines geometry, the amount of studies of the pumping mode instabilities is still relatively low. However, it has increased in last years, due to need for PSP operating regimes optimization. Pump-turbines are subject of operating away from the BEP (best efficiency point), especially in the part load region. The problem can be partly, but not completely, avoided by some new control technics, such as variable speed pump-turbine technology [9]. In case of part load, we can face the distributor hump phenomena, as presented on the Fig. 1. A positive slope in a pumping mode performance curve can be associated to viscous dissipations and unsteady 
flow behavior phenomena, such as vortices, flow separation and recirculation zones.

Due to positive slope, the operating point can vary significantly and uncontrollably, as shown on Fig. 1, what can also lead to the vibrations and to the damage of the machine.

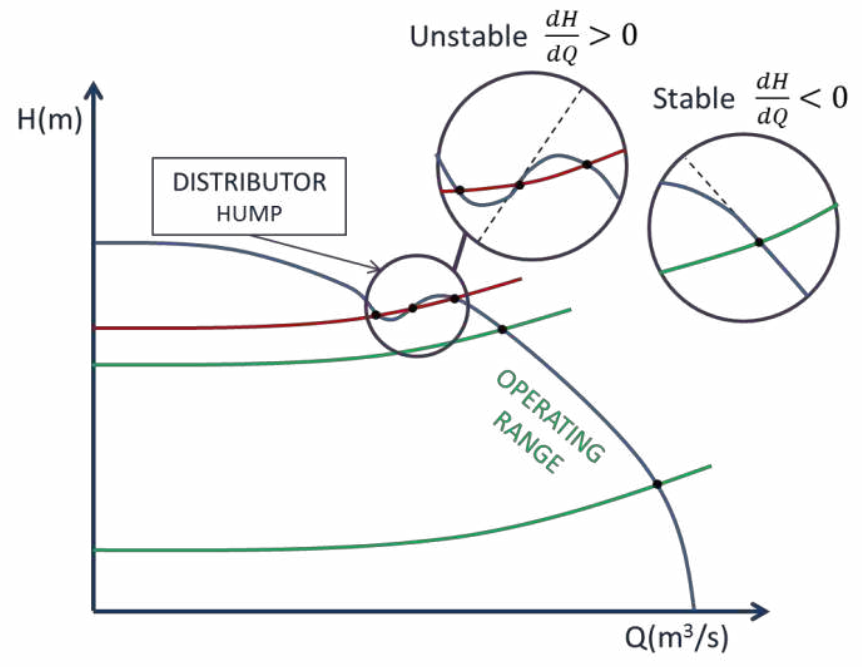

FIGURE 1. PUMPING MODE UNSTABLE CHARACTERISTIC DUE TO DISTRIBUTOR HUMP

Extensive study of the hump zone phenomena was performed in EPFL by Braun [10] during the Hydrodyna project. The rotating stall was well captured experimentally and the flow behavior in the guide vanes channels has been described using LDV techniques. Moreover, the number of stalled channels was investigated.

During the visual observation of the experiment, confirmed by the noise analysis, cavitation vortex appeared in the region of the guide vanes, despite the fact that is located in the high pressure area. According to [10], similar behavior was observed in some cases of the industrial centrifugal pumps. Braun assumed that the origin of the vortex is the flow separation on the hub side of the distributor for the applied geometry.

Numerically, some steady and unsteady 3-dimesional simulations were performed using RANS equations. Detailed numerical study and analysis of the phenomena were made by Pacot [11], who used the Large Eddy Simulation approach. Global rotating stall behavior in one operating point for one opening has been caught quite well, including the area and the frequency of the rotating stall. Nevertheless, those kinds of calculations are very demanding, regarding computational time.

The main difference between the classical centrifugal pumps and the pump-turbines pumping regime is the ability to adapt the guide vanes opening in the pump-turbines, whereas in the centrifugal pumps, the distributor is fixed. Modification of the guide vane opening angles results in different attack angles on the leading edge of the guide vanes. Moreover, it changes also the size of the clearance gap between the impeller and the guide vanes and the gap between the guide vanes and the stay vanes, which may have the effect on the position, the intensity, the shape and the rotation speed of the rotating stall.
A good prediction of the hump shaped performance curve with an ability to simulate the characteristics of the rotating stall for various flow rates and openings can provide a useful tool for the design and optimization procedure.

\section{NUMERICAL SETUP ANALYSIS}

Numerical simulations were performed at LEGI and are based on the high head pump-turbine geometry provided by Alstom Hydro. The numerical domain (Fig. 2) consists of a straight draft tube, 9 runner blades and 20 guide and stay vanes. Instead of a spiral case used at experimental tests, the geometry finishes with an extended diffuser in order to avoid the backflow at the outlet of the domain, which may cause some numerical instabilities. Moreover, presented type of geometry enables the use of the periodicity boundary conditions between the blades. That kind of boundary condition was used during our last paper, presented by Ješe [12] in 2014 and partly during the present study. Constant mass flow rate was used as a boundary condition at the inlet and the static pressure at the outlet of the domain.

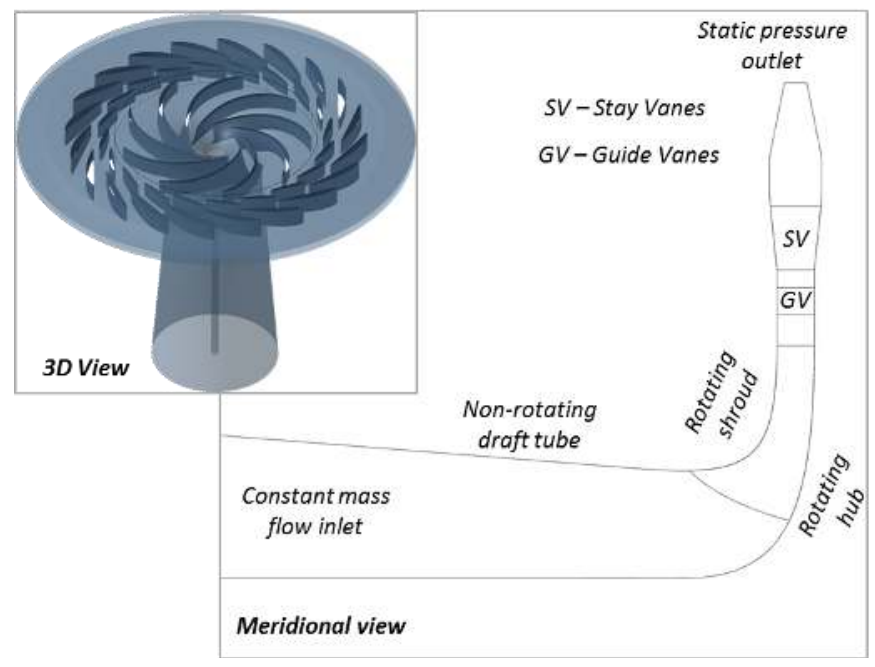

FIGURE 2. DOMAIN WITH BOUNDARY CONDITIONS

Commercial code FINE ${ }^{\mathrm{TM}} /$ Turbo has been used to solve 3D steady and unsteady RANS equations [13] for a homogeneous fluid with a cavitation model that uses barotropic state law for mass transfer, which was initially proposed by [14].

Mesh quality plays an important role for the rotating stall prediction. Several types of meshes were created during the project. For exact prediction of hump shaped performance curve, it is essential to have very dense mesh in the region around the guide and stay vanes. At the part load regime, only the dense mesh enables to accurately predict the first flow separation that consequently leads to the rotating stall, to the increase of losses inside the distributor and to the unstable operating points.

Commercial meshing software AutoGrid 5 has been used to construct an initial one-channel mesh, which consist of around 870.000 cells and keep the $\mathrm{Y}+$ value mostly between 3 and 20 (Fig. 3). Turbulent model k- $\varepsilon$ (with extended wall functions) has 
been applied for all the presented calculations. Minimum skewness reaches $27^{\circ}$ and maximum expansion ration is below 1.8 for all types of mesh.

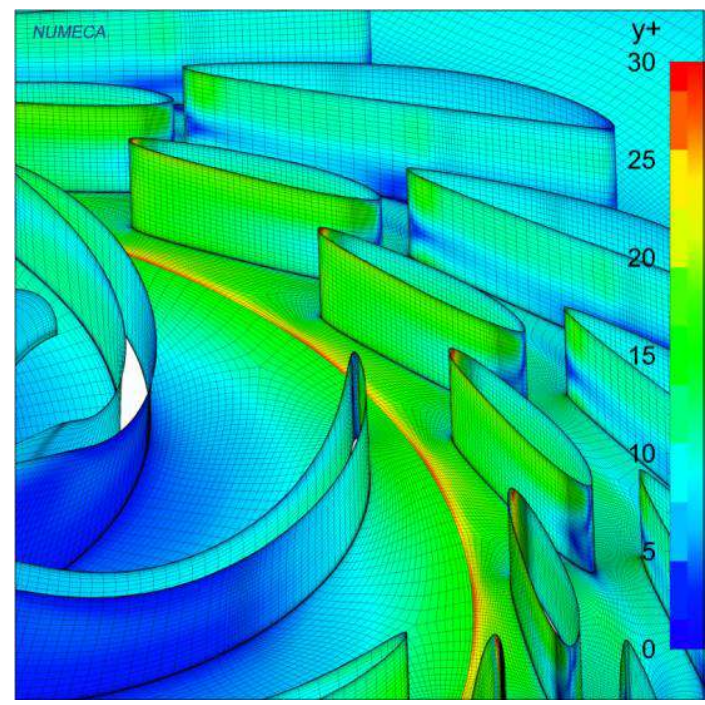

FIGURE 3. Y+ VALUE IN THE DISTRIBUTOR REGION

The presented study shows that for detecting the hump shaped performance one can use periodicity (one channel meshing) as a boundary condition and steady approach. On the other hand, for the analyzing of the rotating stall phenomena, a full distributor mesh is necessary (Tab. 1, 'combined'). For combined mesh, periodicity has been used only in the impeller region. To do an unsteady simulation, one needs to have full mesh in the region of the impeller as well as in the distributor. Table 1 shows types of the meshes and simulations, estimated CPU time to reach the convergence and the output data storage size. Convergence time depends significantly on the position of the operating points. Points closer to the BEP have faster convergence.

TABLE 1. MESH ANALYSIS

\begin{tabular}{|c|c|c|c|}
\hline & periodic & combined & full \\
\hline Type & steady & steady & unsteady \\
\hline Mesh & $0.87 \mathrm{M}$ & $10.7 \mathrm{M}$ & $13.4 \mathrm{M}$ \\
\hline CPU h & $7-20$ & 250 & $270 /$ rot \\
\hline Output & $0.2 \mathrm{~Gb}$ & $1.9 \mathrm{~Gb}$ & $1.7 \mathrm{~Gb} / \mathrm{ts}$ \\
\hline
\end{tabular}

Optimal type of simulation for the exact prediction of the rotating stall is most likely an unsteady simulation with a fullmeshed geometry. However, in that case, the computational requirements are very high. For good stall detection, one needs to use rotating angle $2^{\circ}$ or less, this means at least 180 time steps per one revolution of the machine. Since every time step provides us around $1.7 \mathrm{~Gb}$ of data, around $300 \mathrm{~Gb}$ of storage to save data and around 270 CPU computational hours is needed. Nevertheless, to detect the stall characteristic frequency, which is normally between $2 \%$ and $5 \%$ of the nominal frequency of the machine, at least 30 revolutions must be calculated for each operating point. It is clear that the computational cost of that kind of simulation is high and not easily affordable. Therefore, the main questions of the present study are:

For which operating points unsteady calculations are required? For which type of analysis, the steady calculations with combined or periodical mesh geometries are sufficient?

\section{RESULTS}

The results were analyzed for 4 different openings of the guide vanes (the opening is related to the relative angle to tangential direction). Analysis has been focused on a global prediction of the hump position, on the amplitude of the hump and on the flow patterns in the distributor area. However, the comparison between the experimental and the numerical data can be more qualitative than quantitative, since different total pressure measurement spots were applied. Moreover, the leakage was not taken into account numerically and possible hysteresis effects were not studied for provided experimental data. For each opening, the results were normalized to the corresponding BEP of the experimental data, which may cause some deviation for numerical points away from the BEP.

\section{Guide vanes opening $14^{\circ}$}

The numerical results presented in all the following figures of the performance curve have been obtained for non-cavitating regime, unless stated differently. The line, titled 'Simulation $14^{\circ}$ (Fig. 4.), represents the calculations with the periodic mesh. The hump zone position was detected with an accuracy of $2 \%$ on the flow rate axis and the hump amplitude is around $30 \%$ higher than the experimental one.

In a previous paper [12] it has been shown that the hump was related to the losses, which occur due to flow behavior inside the distributor. To study the effects of the mesh and the periodicity, the combined mesh was created ('Sim-combine $14^{\circ}$ '), using a periodicity in the impeller area and full distributor mesh. The difference between the numerical results occurs only at the part load for flow rates around Q/Qopt=0.7.

Some analysis of the flow patterns in the distributor has been made on the mid-span cutting plane by comparing the meridional velocity distributions. The analysis showed a symmetrical distribution of the flow for all flow rates higher than $\mathrm{Q} / \mathrm{Qopt}=0.87$. On the contrary, for the part load at the hump region $(\mathrm{Q} / \mathrm{Qopt}=0.86)$, the instability is seen as an unsymmetrically distributed flow as seen on the Fig. $4 \mathrm{~b}$. Moreover, the flow shows 4 cells of increased flow rate next to regions of decreased flow rate. The detected phenomenon can be related to a rotating stall. By reducing the flow rate, different shapes and number of the flow cells can be predicted. Between $\mathrm{Q} / \mathrm{Q} o p \mathrm{t}=0.74$ and $\mathrm{Q} / \mathrm{Qopt}=0.83$ the flow is again almost symmetrically distributed around the distributor. On the other hand, flow seems to be very unstable at around Q/Qopt=0.7, which can be seen again as $5-7$ cells of increased flow rate (Fig. 4c). Stable regions with symmetrical distribution of the flow are additionally marked on the figures 4, 6, 7 and 8 . 

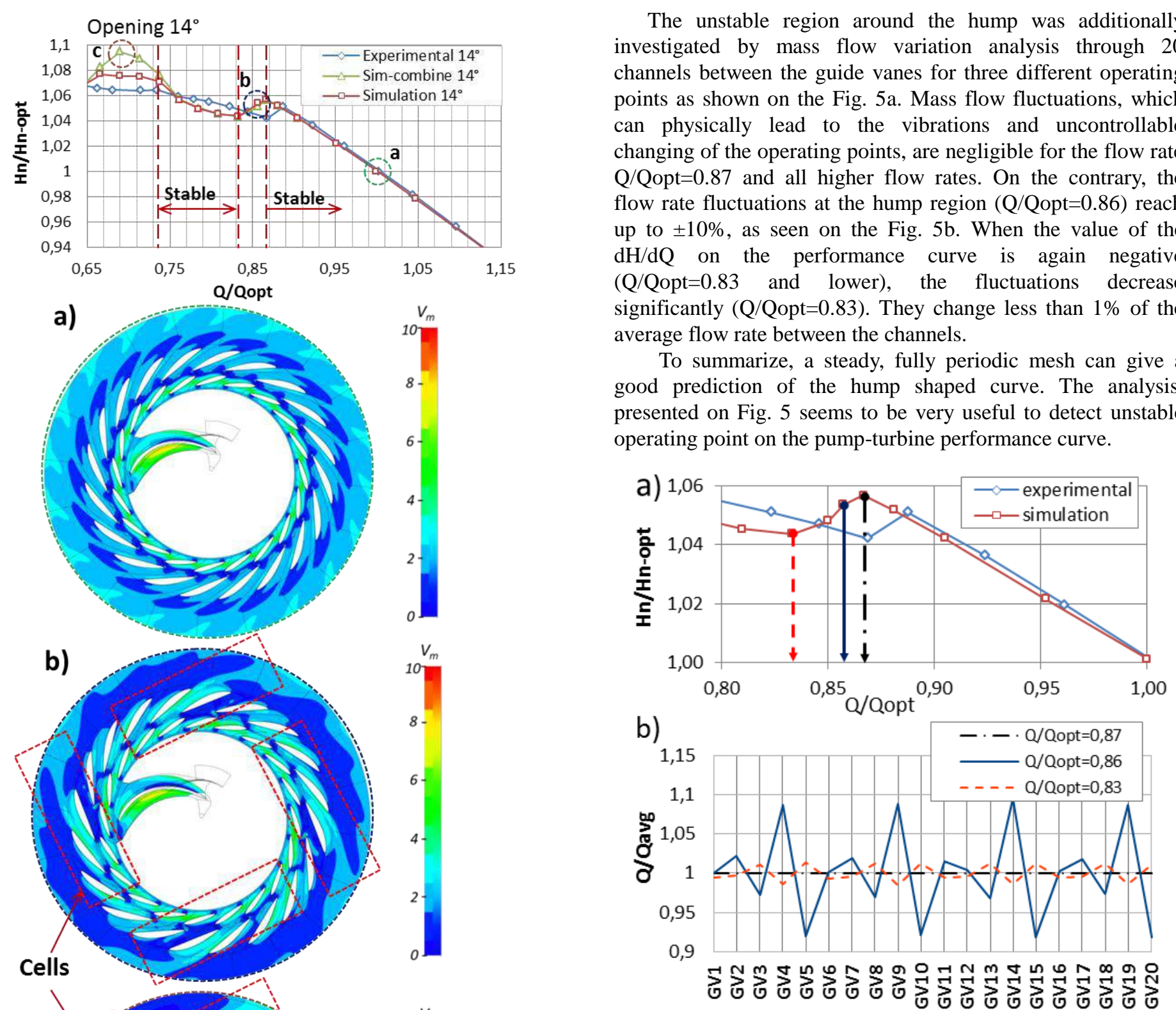

FIGURE 5. a) HUMP OPERATING POINTS b) MASS FLOW ANALYSIS BETWEEN VARIOUS GUIDE VANES CHANNELS FOR OPENING $14^{\circ}$ (COMBINED MESH)

\section{Other guide vanes openings}

$12^{\circ}$ opening. The numerical hump detection for the $12^{\circ}$ opening occurs at the same flow rate as experimental one, also the amplitude is similar, as seen on the Fig. 6. In distributor 4 cells of slightly increased flow rate can be observed. It seems to be less intensive than at $14^{\circ}$ opening. Between the Q/Qopt $=0.75$ and the $\mathrm{Q} / \mathrm{Qopt}=0.85$ the flow is symmetrically distributed around the distributor. By deep decrease of the flow rate, 6 cells of increased flow rate are formed between the Q/Qopt $=0.65$ and the $\mathrm{Q} / \mathrm{Qopt}=0.75$, as seen on Fig. $6 \mathrm{~b}$. 

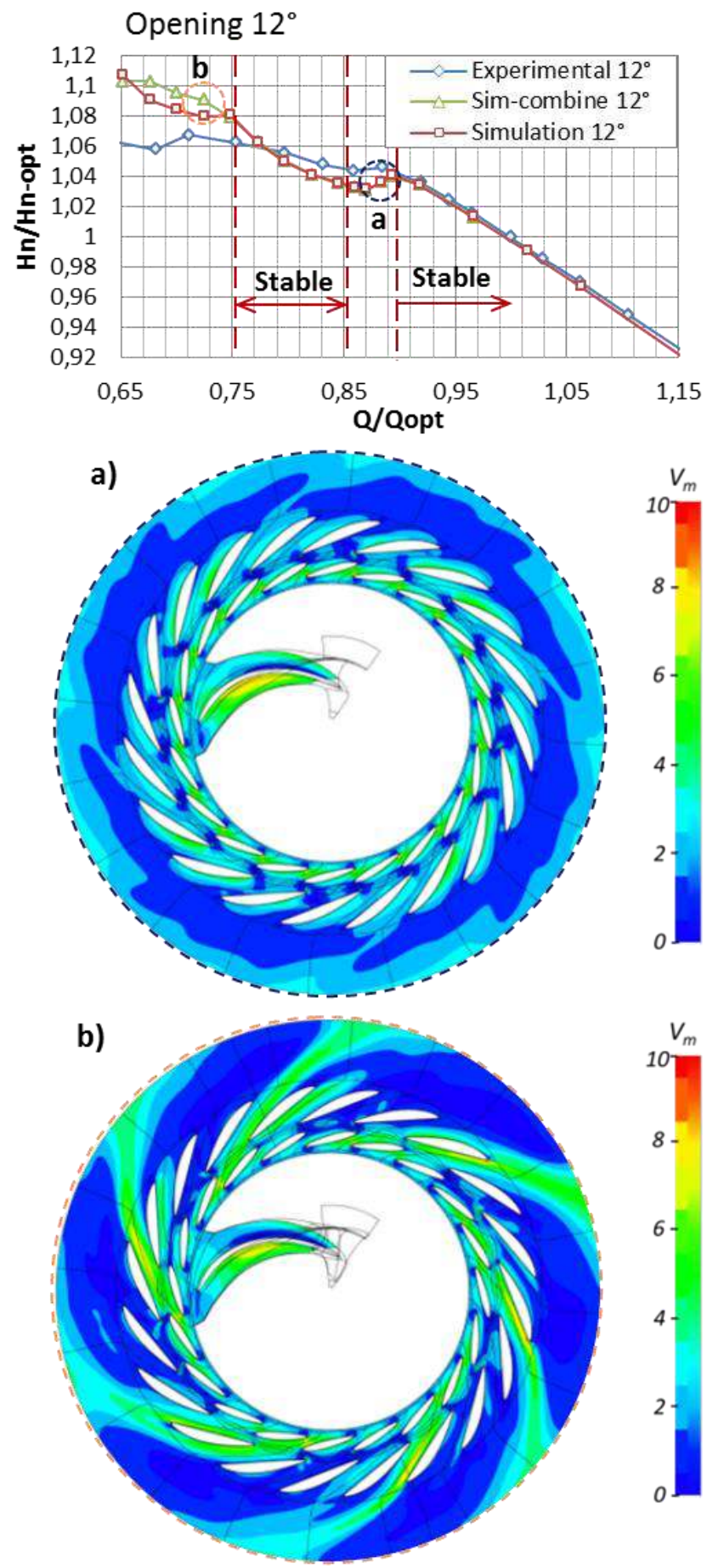

FIGURE 6. PUMPING PERFORMANCE CURVE WITH ANALYSIS OF FLOW PATTERNS (MERIDIONAL VELOCITY "Vm") FOR OPENING $12^{\circ}$

$16^{\circ}$ opening. Guide vane opening $16^{\circ}$ shows experimentally performance curve almost without hump. Numerically, the flow is a bit unstable around Q/Qopt=0.81, as seen on Fig. 7a. However, the distribution of the flow between the guide vane channels seems to be symmetrical and stable for all the flow rates what indicates a good adjustment with the experimental findings that the flow is more stable for this opening, comparing to the others.
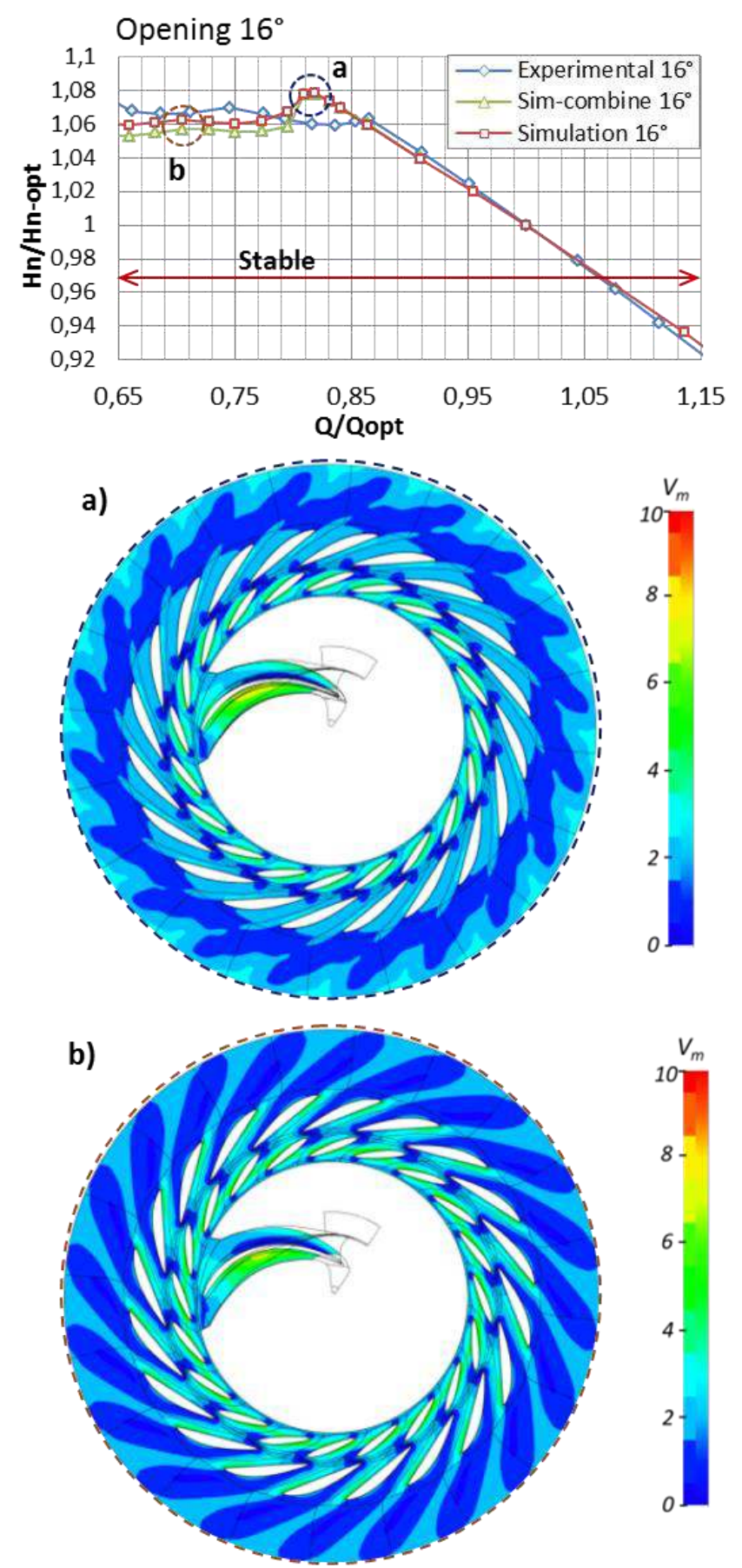

FIGURE 7. PUMPING PERFORMANCE CURVE WITH ANALYSIS OF FLOW PATTERNS (MERIDIONAL VELOCITY "Vm") FOR OPENING $16^{\circ}$

$18^{\circ}$ opening. The biggest analyzed opening $18^{\circ}$ does not have very intensive hump region as seen on Fig. 8 . The unstable behavior has been detected as 8 cells of increased flow rate for all flow rates between the Q/Qopt=0.67 and Q/Qopt=0.81. 

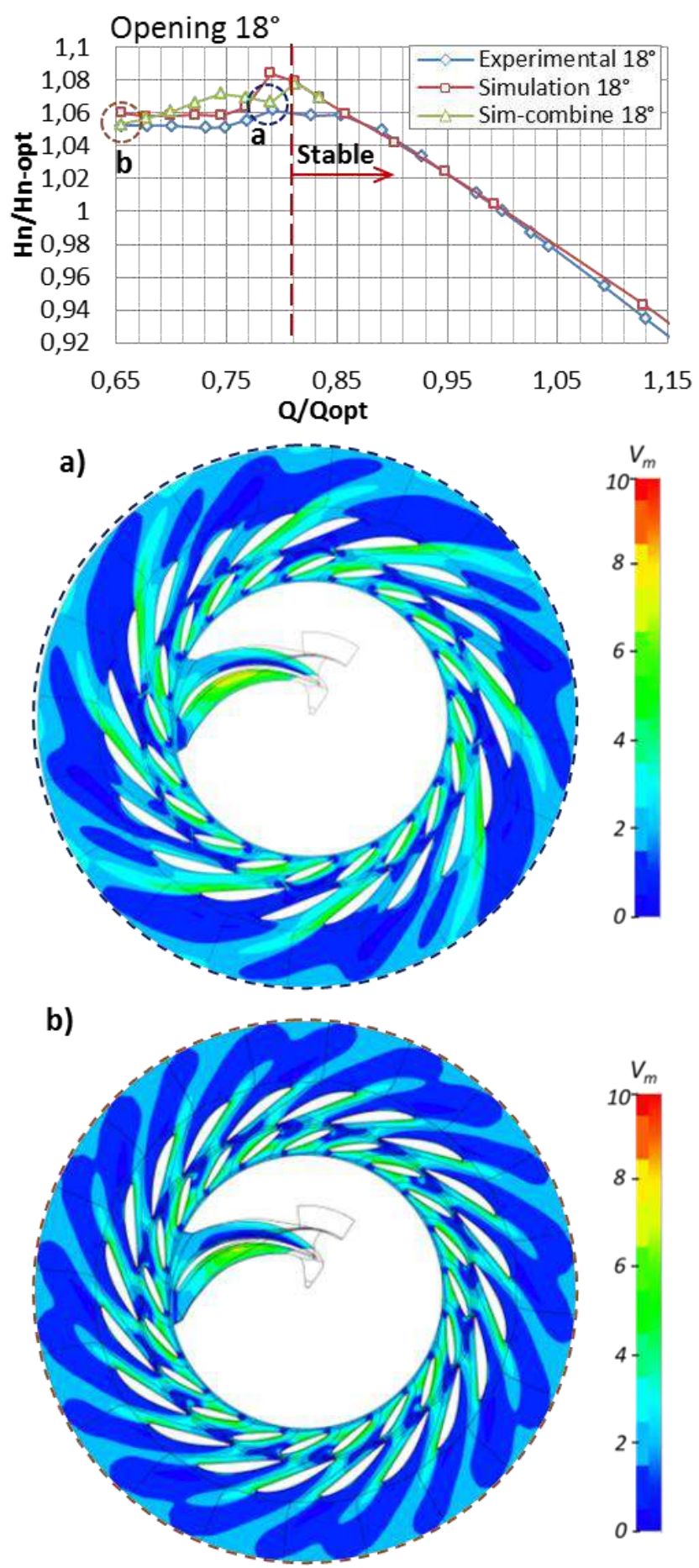

FIGURE 8. PUMPING PERFORMANCE CURVE WITH ANALYSIS OF FLOW PATTERNS (MERIDIONAL VELOCITY "Vm") FOR OPENING $18^{\circ}$

General findings about presented analysis are that the code detects relatively well the stable and the unstable regions. However, some discrepancies occur at the prediction of the performance for certain operating points. For all 4 different guide vanes openings, numerically the performance is slightly over predicted in the unstable, very low part load regions (where cells of increased and decreased flow rate occur) and slightly lower in a stable part load regions. The difference between the periodical mesh and the combined mesh results are seen only in the unstable regions, where rotating stall seems to appear. However, unsteady calculations should be performed in order to improve the analyses.

\section{CAVITATION INFLUENCE ON THE HUMP REGION}

Cavitation influence on the hump region has been investigated phenomenologically with the periodic mesh. Several cavitation analyses related to the cavitation behavior have been presented in [12] for opening $14^{\circ}$. Those analyses have been improved and Fig. 9a presents the hump characteristics obtained for various flow rates and various available NPSH values. The presence of the cavitation reduces the hump amplitude and the positive $\mathrm{dH} / \mathrm{dQ}$ slope is not observed anymore for cavitating regimes at $\mathrm{NPSH}=2.7 \mathrm{~m}$ and $\mathrm{NPSH}=2 \mathrm{~m}$. Similar results have been presented by [15]. The losses in the distributor and decreased performance in the impeller have been investigated for cavitating operating points, comparing to non-cavitating regime (Fig. 9b). Negative values represent the increase of the losses.

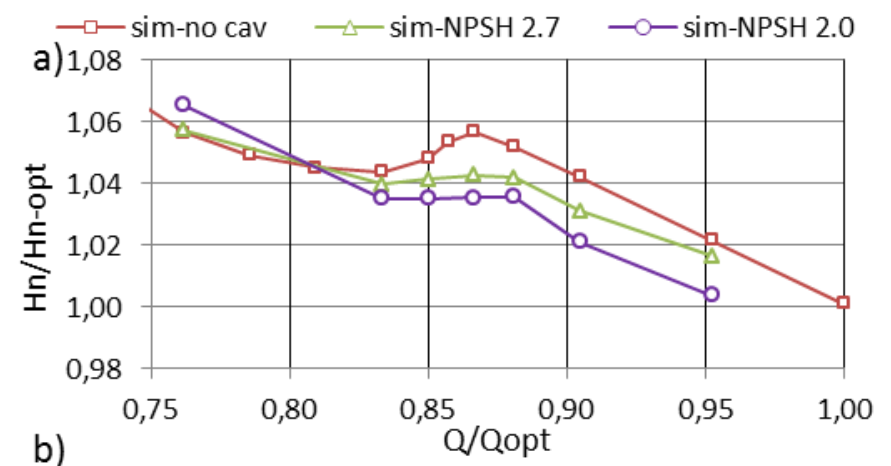

$\square \mathrm{NPSH} 2$.0-dist $\square \mathrm{NPSH} 2.0$-imp $\square \mathrm{NPSH}$ 2.7-dist $\square \mathrm{NPSH}$ 2.7-imp

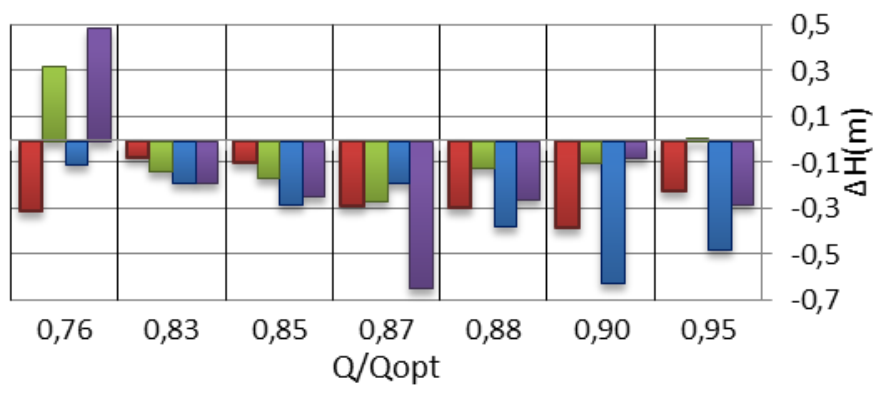

FIGURE 9. OPENING $14^{\circ}$ a) COMPARISON OF PERFORMANCE b) LOSSES COMPARING TO NONCAVITATING REGIME

Cavitation effect on the performance is higher, when the flow rate is higher. Sometimes, at part load, the presence of the cavitation even improves the performance curve due to better conditions in the distributor, as seen on Fig. 9a. Analysis also shows that the cavitation appearance increases losses in the impeller and in the distributor as well, even though the cavitation occurs at the leading edge of the impeller blade. 


\section{CONCLUSIONS AND PERSPECTIVE}

Presented calculations show good agreement with the experimental data close to the hump zone. One channel with periodic boundary conditions seems to give good results for most of the operating points. On the other hand, to detect instabilities that seem to be rotating stall, one needs to use full distributor mesh. The presented approach seems to be very useful for unstable operating point detection on the pumping mode performance curve.

For all 4 analyzed openings, the prediction was slightly over predicted on the pump-turbine performance curve in the very low unstable part load regions and slightly lower in regions of the symmetrically distributed flow around the distributor. Behavior was expected, since the rotating component of the stall cannot be taken into account by steady simulations. Therefore, unsteady simulations should be carried out in order to analyze unsteadiness in the rotating stall.

Experimentally, as well as numerically, one can observe that the flow is more stable for large openings. One of the factors that might have the influence on the flow stability can be a smaller radial gap between the leading edge of the guide vanes and the trailing edge of the impeller blades. Moreover, also the gap between the trailing edge of the guide vanes and the leading edge of the stay vanes reduces at the larger openings, which might have influence on the rotation of the rotating stall. Detailed analysis about the effects of the attack angle, radial gap and the gap between the guide vanes and the stay vanes will be performed in order to improve the analyses.

According to the presented simulations, the presence of the cavitation at the inlet of the impeller reduces the hump amplitude and increases the losses in the impeller as well as in the distributor for most operating points.

\section{ACKNOWLEDGMENTS}

The authors wish to express their gratitude to Alstom Hydro for supplying geometry and experimental results. The laboratory LEGI is part of the LabEx Tec 21 (Investissements d'Avenir - grand agreement $\mathrm{n}^{\circ}$ ANR-11-LABX-0030). PhD study is financed by Slovene Human Resources Development and Scholarship Fund.

\section{REFERENCES}

[1] Frigne P. and Van den Braembussche R., 1984. "Distinction between different types of impeller and diffuser rotating stall in a centrifugal compressor with vaneless diffuser". Trans of ASME Journal of Engineering for Gas Turbines and Power, 106(2):468-474.

[2] Haupt U., Seidel U., Abdel-Hamid A. and Rautenberg M., 1988. "Unsteady flow in a centrifugal compressor with different types of vanes diffuser". Trans of ASME Journal of Turbomachinery, 110(3):293-302.

[3] McDoughal N. M., Compsty N. A. and Hynes T. P., 1990. "Stall inception in axial compressors". Trans of ASME Journal of Turbomachinery, 112(1):116-123

[4] Kline S. J., 1958. "On the nature of stall". Stanford University, Dept. of Mechanical Engineering.

[5] Arndt N., Acosta A. J., Brennen C. E. and Caughey T. K., 1989. "Rotor-stator interaction in a diffuser pump". Trans of ASME Journal of Turbomachinery, 111(3):213-221.

[6] Arndt N., Acosta A. J., Brennen C. E. and Caughey T. K., 1990. "Experimental investigation of rotor-stator interaction in a centrifugal pump with several vaned diffuser". Trans of ASME Journal of Turbomachinery, 112(1):98-108.

[7] Sano T., Nakamura Y., Yoshida Y. and Tsujimoto Y, 2002. "Alternate blade stall and rotating stall in a vaned diffuser". JSME International Journal Series B, 45(4):810-819.

[8] Sano T., Yoshida Y., Tsujimoto Y., Nakamura Y. and Matsushima T., 2002. "Numerical study of rotating stall in a pump vaned diffuser". Trans of ASME Journal of Fluids Engineering, 124(2):363-370.

[9] Ciocan G. D., Teller O. and Czerwinski F., 2012. "Variable speed pump-turbines technology". University "Politehnica" of Bucharest Scentific Bulletin, Series D: Mechanical engineering, 74(1):33-42.

[10] Braun O., 2009. "Part load flow in radial centrifugal pumps". PhD Thesis, EPFL, Lausanne.

[11]Pacot O., 2014. "Large scale computation of the rotating stall in a pump-turbine using an overset finite element large eddy simulation numerical code". PhD Thesis, EPFL, Lausanne.

[12] Ješe U., Fortes-Patella R. and Antheaume S., 2014. "High head pump-turbine: Pumping mode numerical simulations with a cavitation model for off-design conditions". IOP Conference Series: Earth and Environmental Science, 22 032048

[13] Pouffary B., Fortes-Patella R., Reboud J-L. and Lambert PA, 2008. Numerical simulations of 3D cavitating flows: analysis of cavitation head drop in turbomachinery". Trans of ASME Journal of Fluids Engineering, 130061301

[14]Delannoy Y. and Kueny J-L., 1990. "Two phase flow approach in unsteady cavitation modeling" Cavitation and Multiphase Flow Forum pp. 153-158.

[15] Amblard H., Borigiani G., Guiton P., Henry P. and Thalmann R., 1985. "Comportement des turbines Francis et des pompes-turbines a debit partiel". SHF, Comite Technique, session $\mathrm{n}^{\circ} 127$, Paris. 